\title{
Corridor Volatility Risk AND EXPECTED RETURNS
}

\author{
GEORGE DOTSIS* and NIKOLAOS VLASTAKIS
}

\begin{abstract}
This paper examines the pricing of volatility risk using SPX corridor implied volatility. We decompose model-free implied volatility into various components using different segments of the cross-section of out-of-the money put and call option prices. We find that only model-free volatility computed from the cross-section of out-of-the-money call option prices carries a significant negative risk premium in the cross-section of stock returns and subsumes all relevant information for forecasting future volatility. Our empirical results provide strong evidence that SPX out-of-the money put option prices do not contain useful information for pricing aggregate volatility risk in the cross-section of stock returns. (C) 2015 Wiley Periodicals, Inc. Jrl Fut Mark
\end{abstract}

\section{INTRODUCTION}

Stochastic return volatility plays a crucial role in the determination of asset returns. In the equity markets, a rise in volatility is usually associated with bad states and a deterioration of the investment opportunity set. If volatility risk is systematic, asset pricing theory suggests that investors are willing to pay a premium for buying protection against such unfavorable shocks and therefore stocks that do well (bad) when volatility increases should carry a low (high) premium.

Previous studies in the literature have used either option implied information or/and the cross-section of stock returns to study the market price of volatility risk. Bakshi and Kapadia (2003) analyze the profits/losses of delta hedged option portfolios on SPX and Carr and Wu (2009) use the difference between the realized volatility and the volatility swap rate to quantify the volatility risk premium in SPX returns. Bates (2000), Chernov and Ghysels (2000), Pan (2002), and Eraker (2004) use parametric stochastic volatility models fitted to SPX option prices and index returns to estimate the volatility risk premium. Other studies examine the pricing of volatility risk in the cross-section of stock returns. Ang, Hodrick, Xing, and Zhang (2006), use the implied volatility VXO as a proxy for market volatility and Adrian and Rosenberg (2008) use historical data and a two component GARCH model for modeling volatility dynamics. Cremers, Halling, and Weinbaum (2013) use investable option strategies and examine the pricing of aggregate jump and volatility risk. All studies find that volatility

George Dotsis is at Department of Economics, University of Athens, Athens, Greece. Nikolaos Vlastakis is at Essex Finance Centre and Essex Business School, University of Essex, Colchester, UK. We would like to thank an anonymous referee for helpful comments and suggestions that have substantially improved the paper. Any remaining errors are our responsibility alone.

JEL classification: G10, G12

* Correspondence author, Department of Economics, University of Athens, Sofokleous \& Aristidou str., office 519, 10559, Athens, Greece. Tel: +302103689454, Fax: +302103689471, e-mail: gdotsis@econ.uoa.gr 
risk carries a negative premium in the cross section of stock returns. DeLisle, Doran, and Peterson (2011) use the VXO index and find that only upside changes in implied volatility are priced in the cross-section of stock returns.

In this paper we also examine the price of volatility risk in the cross-section of stock returns. Our empirical analysis is based on model-free implied volatility computed from the cross-section of out-of-the money SPX put and call option prices. The main contribution of this paper is that in the empirical analysis we use the concept of model-free corridor implied volatility introduced by Carr and Madan (1998) and developed further by Andersen and Bondarenko (2010). We break the implied volatility into various components that capture market volatility risk over different intervals for the underlying asset price. This decomposition allows us to separate the incremental information of the various segments of the cross-section of out-of-the money put and call option prices with respect to the pricing of systematic volatility risk.

Our study is motivated by empirical results in the literature which show that the SPX out-of the-money put options market may be disconnected from the equity market. After the US stock market crash in 1987 the SPX option market is consistently displaying a smirk pattern when implied volatility is plotted against moneyness. According to the smirk pattern out-of-the-money put options are consistently more expensive than the corresponding out-ofthe money call options. Rubinstein (1994) refers to this phenomenon as "crash-o-phobia" and attributes it to the strong demand for out-of-the-money put options to hedge against market crashes. Jackwerth (2000) and Jones (2006) find that the returns from writing SPX out-of-the money put options are extraordinarily high and cannot be explained by known risk factors that affect stock returns. Bates (2008) argues that the out-of-the money put option market operates more like an insurance market for crash risk. Theories of demand based option pricing (see Bollen and Whaley, 2004 and Garleanu, Pedersen and Poteshman, (2009) argue that SPX out-of-the money put option prices are mainly driven by the demand pressure by hedgers who seek portfolio insurance. If out-of the-money put option prices are driven by factors which do not affect the pricing of stocks, it is natural to assume that they will also not contain useful information with respect to the price of volatility risk in the crosssection of stock returns. This is the main hypothesis tested in this paper.

We decompose total implied volatility into model-free implied volatility extracted from out-of-the-money calls and model-free implied volatility extracted from out-of-the-money puts using various segments of options moneyness range. We also calculate measures of model-free volatility that are designed to capture tail risk and these measures are computed from the crosssection of deep out-of-the-money put option prices. Our empirical design is similar to that of Ang, Hodrick, Xing, and Zhang (2006). We use all stocks on NYSE, AMEX and the NASDAQ between January 1996 to December 201 1, to create quintile portfolios based on factor loadings of stock returns to innovations in various measures of corridor implied volatility.

Consistent with our hypothesis, we find that only model-free volatility computed from out-of the-money calls carries a significant negative risk premium in the cross-section of stock returns. Portfolios with high factor loadings to innovations in out-of the-money call implied volatility are perceived to be less risky and earn lower returns than portfolios with low factor loadings. In a series of empirical tests we don't find any strong evidence that out-of themoney put option implied volatility or volatility tail risk is priced in the cross-section of stock returns. In the cross-sectional tests we also use innovations in the VIX index as another proxy for volatility risk. The model-free VIX index provided by CBOE is a popular measure of investor fear gauge and it is computed as a weighted average of out-of-the-money call and put option prices. We find that the VIX index is not a priced factor in the cross-section of stock returns and this is due to the fact that part of the VIX dynamics is driven by the prices of outof-the-money put options. This finding suggests that the VIX futures contracts currently offered by the CBOE may not be suitable for hedging volatility risk in equity portfolios. 
The empirical results from the quintile portfolio returns suggest that model-free volatility computed from the cross-section of out-of the-money calls is probably a better proxy for future realized volatility. To test if this is indeed the case, we run predictive regressions to examine which implied volatility measure is most capable of forecasting future realized SPX volatility. We find that model-free volatility computed from out-of the-money call option prices subsumes all relevant information for forecasting future volatility.

The remainder of the paper is structured as follows. In the next Section we describe the methodology for constructing corridor implied volatility. In Sections 3 and 4 we present the empirical results on the pricing of volatility risk. Section 5 examines the ability of the various model-free volatility measures to predict future realized volatility. The last Section concludes and presents the implications of the study.

\section{CORRIDOR IMPLIED VOLATILITY}

Suppose that an asset's dynamics is governed by the following diffusion process:

$$
d S_{t}=\mu_{t} d t+\sigma_{t} d B_{t}
$$

where, $S_{t}$ is the price of the asset at time $t, B_{t}$ is a standard Brownian motion, $\mu_{t}$ is the drift component and $\sigma_{t}$ is the diffusion component. We assume that the volatility component evolves stochastically over time. The annualized realised volatility of the asset's log returns over the time interval $[t, T]$ is given by:

$$
V(t, T)=\left(\frac{1}{T-t} \int_{t}^{T} \sigma_{s}^{2} d s\right)
$$

The annualized corridor return volatility is defined as

$$
V_{C}(t, T)=\left(\frac{1}{T-t} \int_{t}^{T} \sigma_{s}^{2} 1_{S_{t} \in\left[B_{L}, B_{U}\right]} d s\right)
$$

where, $1_{S_{t} \in\left[B_{L}, B_{U}\right]}$ is an indicator function that that takes the value of 1 if the asset price is inside the two barriers and zero otherwise.

We construct model-free implied volatility using the method developed by Britten-Jones and Neuberger (2000). This method computes the risk-neutral volatility from the crosssection of out-of-money (OTM) call and put option prices. For a given horizon $T-t, \tau$ he riskneutral expectation of volatility in (1) is given by:

$$
E^{Q}[V(t, T)]=\frac{2 \exp (r(T-t))}{T-t}\left[\int_{0}^{F_{0}} \frac{P(t, T ; K)}{K^{2}} d K+\int_{F_{0}}^{\infty} \frac{C(t, T ; K)}{K^{2}} d K\right]
$$

where $F_{O}$ is the forward price of the underlying with maturity $T, r$ is the risk-free rate asset and $C(t, T, K)$ and $P(t, T, K)$ are OTM call and put option prices, respectively, with strike price $K$ and maturity $T .{ }^{1}$ The model-free implied volatility can be decomposed into two components.

\footnotetext{
${ }^{1}$ Equation (1) is an excellent approximation to the risk-neutral quadratic variation of the logarithm of the asset price when there are relatively small jumps in the stock price (Carr and $\mathrm{Wu}(2009))$. However, if there is an extreme jump, e.g., 2008 financial crisis, then the approximation error can be very large. In fact, Andersen et al. (2015) discuss issues related to jumps and discrete sampling. We would like to thank an anonymous referee for pointing out this issue.
} 
The component computed from OTM calls $(V C)$ and the component computed from OTM puts $(V P)$ :

$$
\begin{aligned}
& V C(t, T)=\frac{2 \exp (r(T-t))}{T-t} \int_{F_{0}}^{\infty} \frac{C(t, T ; K)}{K^{2}} d K \\
& V P(t, T)=\frac{2 \exp (r(T-t))}{T-t} \int_{0}^{F_{0}} \frac{P(t, T ; K)}{K^{2}} d K
\end{aligned}
$$

where, $V(t, T)=V C(t, T)+V P(t, T)$.

The calculation of implied volatility in (3) or (4) and (5), requires the use of options with strike prices spanning from zero to infinity. Andersen and Bondarenko (2010) develop a method for defining the strike range over which the implied volatility is calculated. Their method allows the decomposition of the implied volatility into various components that capture market volatility over different intervals of the underling's risk neutral distribution. They use the ratio $R(K)$ which is given by:

$$
R(K)=\frac{P(t, T, K)}{C(t, T, K)+P(t, T, K)}
$$

Suppose that we want to truncate the left tail by $q$ percent and we want to find which OTM put options to use for the calculation of VP in expression (3). We need to find the strike price $K_{q}$ for which $\mathrm{R}\left(K_{q}\right)=q$ and choose OTM put option prices that have a strike price higher than $K_{q}$. The function $R(K)$ and its inverse $K_{q}=R^{-1}(q)$ can be easily obtained from the observed market prices of OTM call and put option prices. Note that the quotient $K_{0.5}$ is equal to the mean of the risk neutral distribution. For example if we choose the strike prices, $K_{0.01}=R^{-1}(0.01)$ and $K_{0.99}=R^{-1}(0.99)$ we truncate the left tail of the underlying's risk neutral density by $1 \%$ and the right tail by $1 \%$, respectively.

This type of decomposition allows us to examine in a consistent manner the informational content of option prices at different moneyness levels. In the empirical analysis we use various symmetric lower $\left(B_{L}\right)$ and upper $\left(B_{U}\right)$ bounds to define the moneyness range at which implied volatility is calculated. Andersen and Bondarenko (2010) show that the implied volatility with lower $\left(B_{L}\right)$ and upper $\left(B_{U}\right)$ bounds is analogous to the risk neutral expectation of corridor volatility in (2) and it is given by:

$$
\begin{aligned}
& E^{Q}(V(t, T))=\frac{2 \exp (r(T-t))}{T-t}\left[\int_{B_{L}}^{F_{0}} \frac{P(t, T ; K)}{K^{2}} d K+\int_{F_{0}}^{B_{U}} \frac{C(t, T ; K)}{K^{2}} d K\right] \\
& V C(t, T)=\frac{2 \exp (r(T-t))}{T-t} \int_{F_{0}}^{B_{U}} \frac{C(t, T ; K)}{K^{2}} d K \\
& V P(t, T)=\frac{2 \exp (r(T-t))}{T-t} \int_{B_{L}}^{F_{0}} \frac{P(t, T ; K)}{K^{2}} d K
\end{aligned}
$$

In the subsequent empirical analysis we use model-free volatilities computed from (7) when $B_{U}$ takes the values $R^{-1}(0.01), R^{-1}(0.05), R^{-1}(0.1), R^{-1}(0.15), R^{-1}(0.2), R^{-1}(0.25)$, and $B_{L}$ takes the values $R^{-1}(0.99), R^{-1}(0.95), R^{-1}(0.90), R^{-1}(0.85), R^{-1}(0.80), R^{-1}(0.75)$. The model-free volatility which is computed from the full cross-section of OTM put and call option prices is denoted as VF, the model-free volatility which is computed from the full cross-section of OTM puts is denoted as VPF and the model-free volatility which is computed from the full cross-section of OTM calls is denoted as VCF. The model-free volatility which is 
computed from the cross-section of OTM put and call option prices that truncates the left and right tails of the underlying's risk-neutral return distribution by $1 \%$ is denoted as V99. The model-free volatility which is computed from the cross-section of OTM puts that truncates the left tail by $1 \%$ is denoted as VP99 and the model-free volatility which is computed from the cross-section of OTM calls that truncates the right tail by $1 \%$ is denoted as VC99. We similarly define model-free volatilities that correspond to 5\%, 10\%, 15\%, 20\%, and $25 \%$ truncation levels of the left and right tails of the underlying's risk neutral distribution (a total of 21 model-free volatilities).

In the ensuing empirical analysis we also use the CBOE volatility indices VIX and VXO. The VIX index is a measure of model-free volatility and it is computed using the full cross-section of SPX OTM put and call option prices. The VXO index is based on S\&P 100 options and it is computed as the average of the Black and Scholes (1973) implied volatilities on two near-the-money calls and two near-the-money puts. The main difference between the two indices is that the VXO does not contain information from the full cross-section of OTM options. Note that Ang, Hodrick, Xing, and Zhang (2006) use the VXO index and not the VIX index when they study the price of volatility risk in the cross-section of stock returns.

We also construct three measures that capture volatility risk in the left tail of the underlying's risk neutral density:

$$
V P(t, T)=\frac{2 \exp (r(T-t))}{T-t} \int_{0}^{B_{L}} \frac{P(t, T ; K)}{K^{2}} d K
$$

where, $B_{L}$ takes the values $R^{-1}(0.01), R^{-1}(0.05), R^{-1}(0.1)$.

The model-free volatility which is computed from the cross-section of deep OTM puts that corresponds to the $1 \%$ of the left tail of the underlying's risk-neutral return is denoted as VPT1, the model-free volatility which is computed from the cross-section of deep OTM puts that corresponds to the 5\% of the left tail is denoted as VPT5 and the model-free volatility which is computed from the cross-section of deep OTM puts that corresponds to the $10 \%$ of the left tail is denoted as VPT10.

\section{DATA DESCRIPTION}

We construct the various corridor implied volatility measures on a daily frequency using options data on SPX from Option Metrics Ivy Database. Our sample period is from January 1996 to December 2011. From the row data we select only OTM call and put option prices. Options with strike prices of more than $103 \%$ of the forward index level (K/ $\mathrm{F}>1.03)$ and call options with strike prices of less than $97 \%$ of the forward index level (K/ $\mathrm{F}<0.97)$ are eliminated. The forward index level is calculated as in Jiang and Tian (2007) from at-the money options using the put-call parity. We use the average bid and ask prices for each option contract and eliminate contracts with zero bids and average prices less than $\$ 3 / 8$. For each option maturity available we use a cubic spline to interpolate implied volatilities across moneyness levels $(K / F)$. For moneyness levels below (above) the lowest (highest) available moneyness level in the row data, we use the implied volatility at the lowest (highest) strike price. After this interpolation and extrapolation procedure, we construct a fine grid of 1000 implied volatilities for moneyness levels between $0.01 \%$ and $300 \%$ relative to the spot price.

We convert the implied volatilities into option prices using the Black and Scholes model and use a trapezoidal rule similar to that proposed by Jiang and Tian (2007) to approximate 
the integrals in (7) and (8). We calculate the implied volatilities only when there are at least two OTM call prices and two OTM put prices available. ${ }^{2}$

All model-free volatility measures have a constant maturity of 30 days. To construct the constant maturity volatilities, we first compute the implied volatilities using options that expire within the two nearest maturities (less than 30 days and greater than 30 days). Then we linearly interpolate between the two maturities to construct the 30-day model-free volatility. We compute model-free volatilities that correspond to $5 \%, 10 \%, 15 \%, 20 \%$ and $25 \%$ truncation levels of the left and right tails of the underlying's risk neutral distribution. The moneyness levels implied by the different upper and lower levels used in Equation (7) range from 1.11 (upper) to 0.82 (lower) for the $1 \%$ truncation level to 1.03 (upper) to 0.98 (lower) for the $25 \%$ truncation level.

Table I reports the descriptive statistics of the model-free volatilities that correspond to the various truncated points described in Section 2 . The volatility calculated from the crosssection of OTM calls is consistently lower than the volatility computed from the cross-section of OTM puts. This is consistent with the implied skew in the SPX options market where OTM puts are more expensive relative to OTM calls. The implied volatilities computed from the cross-section of OTM calls are consistently less volatile with smaller skewness and kurtosis compared the volatilities computed from the cross-section of OTM puts. Figure 1 plots the time series of VF, VPF, and VCF for the time period 1996-2011. It is evident from Figure 1, that most of the spikes in VF during times of market downturns are mainly generated by VPF which is the volatility part that corresponds to the cross-section of OTM put prices.

Table II reports the correlation coefficients of daily changes in VF, VPF, and VCF with respect the excess return on the market portfolio (MKT), the size factor (SMB), the value factor (HML) the momentum factor (UMD) and the liquidity factor (LIQ) of Pastor and Stambaugh (2003). The data on MKT, SMB, HML and UMD were taken from Professor Ken French's website and the liquidity factor from Professor Lubos Pastor's website. VF is mainly correlated with VPF (0.98) and to a lesser extent with VCF (0.93). VCF has a negative correlation of -0.73 with the market return while VPF has a negative correlation of -0.66 . All model-free volatilities have a positive correlation with the SMB and UMD factors and a negative correlation with the HML. The LIQ factor is negatively correlated with VF, VCF, and VPF.

\section{EMPIRICAL RESULTS}

\subsection{Portfolio Sorts}

We use all stock returns included in the CRSP NYSE/AMEX/NASDAQ daily file from January 1996 to December 2011 to create quintile portfolios based on factor loadings of stock returns to innovations in various measures of model-free volatility. Innovations in model-free volatilities are proxied by daily changes in volatility levels. Every month in our sample period we use daily data to estimate factor loading of individual stock returns with respect to innovations in model-free volatility:

$$
R_{i, t}-R_{f, t}=a_{i}+\beta_{i M} M K T_{t}+\beta_{i, V} \Delta V_{t}+\varepsilon_{i, t}
$$

\footnotetext{
${ }^{2}$ The qualified OTM calls are approximately $25 \%$ of the total options used in the calculations. The market for SPX 500 OTM calls is more liquid compared to the individual equity option market studied by Xing, Zhang and Zhao (2010).
} 
TABLE I

Descriptive Statistics of Model-Free Volatilities

\begin{tabular}{|c|c|c|c|c|}
\hline Volatility & Mean & St. Dev & Skewness & Kurtosis \\
\hline \multicolumn{5}{|c|}{$0 \%$ truncation } \\
\hline VF & 0.057 & 0.058 & 4.39 & 28.39 \\
\hline VPF & 0.037 & 0.040 & 4.46 & 29.17 \\
\hline VCF & 0.020 & 0.018 & 4.24 & 27.68 \\
\hline \multicolumn{5}{|c|}{$1 \%$ truncation } \\
\hline V99 & 0.053 & 0.054 & 4.38 & 28.48 \\
\hline VP99 & 0.033 & 0.037 & 4.45 & 29.16 \\
\hline VC99 & 0.020 & 0.018 & 4.23 & 27.66 \\
\hline \multicolumn{5}{|c|}{$5 \%$ truncation } \\
\hline V95 & 0.045 & 0.046 & 4.43 & 29.01 \\
\hline VP95 & 0.027 & 0.030 & 4.51 & 29.85 \\
\hline VC95 & 0.018 & 0.017 & 4.26 & 27.87 \\
\hline \multicolumn{5}{|c|}{$10 \%$ truncation } \\
\hline V90 & 0.039 & 0.040 & 4.46 & 29.53 \\
\hline VP90 & 0.022 & 0.025 & 4.56 & 30.48 \\
\hline VC90 & 0.017 & 0.015 & 4.29 & 28.26 \\
\hline \multicolumn{5}{|c|}{$15 \%$ truncation } \\
\hline V85 & 0.033 & 0.034 & 4.48 & 29.77 \\
\hline VP85 & 0.018 & 0.021 & 4.58 & 30.66 \\
\hline VC85 & 0.015 & 0.014 & 4.31 & 28.66 \\
\hline \multicolumn{5}{|c|}{$20 \%$ truncation } \\
\hline V80 & 0.028 & 0.030 & 4.52 & 30.27 \\
\hline VP80 & 0.014 & 0.017 & 4.63 & 31.24 \\
\hline VC80 & 0.014 & 0.013 & 4.32 & 28.75 \\
\hline \multicolumn{5}{|c|}{$25 \%$ truncation } \\
\hline V75 & 0.024 & 0.025 & 4.52 & 30.27 \\
\hline VP75 & 0.011 & 0.014 & 4.61 & 30.97 \\
\hline VC75 & 0.012 & 0.011 & 4.34 & 29.20 \\
\hline
\end{tabular}

Descriptive statistics of SPX model-free volatilities. The model-free volatility which is computed from the segment of the crosssection of OTM put and call option prices that truncates the left and right tails of the underlying's risk-neutral return distribution by $1 \%$ is denoted as V99. The model-free volatility which is computed from the segment of the cross-section of OTM put that truncates the left tail by $1 \%$ is denoted as VP99 and the model-free volatility which is computed from the segment of the cross-section of OTM calls that truncates the right tail by $1 \%$ is denoted as VC99. We similarly define model-free volatilities that correspond to $5 \%, 10 \%$, $15 \%, 20 \%$, and $25 \%$ truncation levels of the left and right tails of the underlying's risk neutral distribution. VF, VPF, and VCF are computed using the full cross-section of option prices ( $0 \%$ truncation). The data are daily and cover the period from January 1996 to December 2011 (3,918 observations for each series). 


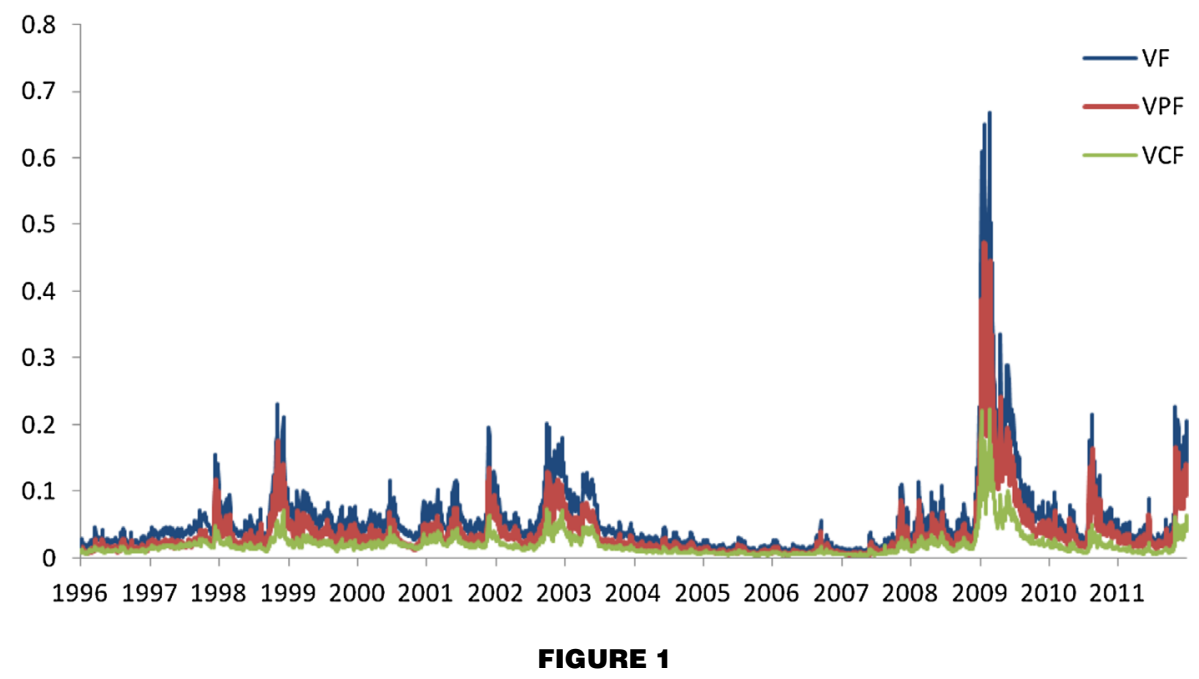

Time series of daily implied volatilities, where VF $=\mathrm{VPF}+\mathrm{VCF}$. VF is the model-free volatility computed from the full cross-section of OTM calls and puts, VPF is the model-free implied volatility computed from the full cross-section of OTM puts and VCF is the model-free implied volatility computed from full cross-section of OTM calls. The data are daily observations and the sample period is

from January 1996 to December 2011. [Color figure can be viewed in the online issue, which is available at wileyonlinelibrary.com.]

where the variable $\Delta V_{t}=V_{t}-V_{\mathrm{t}-1}$ denotes daily volatility innovations. We use a total of 21 different model-free volatilities described in Section 2. For comparison purposes we also use the CBOE volatility indices, VIX and VXO.

At the end of each month, we sort stocks into quintiles based on the value of the estimated loadings $\left(\beta_{i, V}\right)$, where stocks in quintile 1 have the lowest coefficients and stocks in quintile 5 have the highest coefficients. Then we record the value-weighted daily returns of the quintile portfolios over the next month and subsequently the estimation window is rolled

TABLE II

Correlation Coefficients

\begin{tabular}{|c|c|c|c|c|c|c|c|c|}
\hline & $V F$ & $V P F$ & $V C F$ & MKT & $S M B$ & $H M L$ & $U M D$ & LIQ \\
\hline VF & 1 & & & & & & & \\
\hline VPF & 0.986 & 1 & & & & & & \\
\hline VCF & 0.934 & 0.860 & 1 & & & & & \\
\hline MKT & -0.706 & -0.660 & -0.73 & 1 & & & & \\
\hline SMB & 0.092 & 0.082 & 0.10 & 0.009 & 1 & & & \\
\hline HML & -0.028 & -0.019 & -0.04 & -0.132 & -0.13 & 1 & & \\
\hline UMD & 0.218 & 0.190 & 0.26 & -0.275 & 0.09 & -0.265 & 1 & \\
\hline LIQ & -0.147 & -0.140 & -0.146 & 0.249 & 0.114 & -0.067 & -0.015 & 1 \\
\hline
\end{tabular}

Correlation coefficients between daily changes in model-free volatilities, the excess market return (MKT), the size factor (SMB), the value factor (HML) and the momentum factor (UMD). VF is the model-free volatility computed from the full cross-section of OTM calls and puts, VPF is the model-free implied volatility computed from the full cross-section of OTM puts and VCF is the model-free implied volatility computed from full cross-section of OTM calls. The data are daily and cover the period from January 1996 to December 2011 (3,918 observations for each series). The correlation coefficients of the liquidity factor (LIQ) are based on monthly data. 
1 month forward and the process is repeated. The value-weighting is based on stock's capitalization at the end of the formation period (end of month).

In Table III we report the monthly returns of the quintile portfolios and the spread in average returns between the 5 th quintile portfolio and the 1 st quintile portfolio. We also report the alpha of the 5-1 spread with respect to the Fama and French (1993) three factor model augmented by the momentum factor of Carhart (1997). The monthly returns of the quintile portfolios are obtained by multiplying the average daily returns within each month by 22 . Similarly, the alpha is also multiplied by 22 . The $t$-statistics are adjusted for autocorrelation and heteroskedasticy using the Newey and West (1987) estimator with 12 lags.

The market price of risk of innovations in model-free volatility computed from the crosssection of OTM calls is consistently negative and highly significant for truncation levels ranging from $0 \%$ to $20 \%$. The spread in average returns between the 5 th quintile portfolio and the 1 st quintile portfolio suggests that the price of volatility risk is approximately $-10 \%$ per annum. The alphas are also highly significant with $t$-statistics ranging from -3.33 to -2.65 . In sharp contrast, the spread in average returns between the 5 th quintile portfolio and the 1 st quintile portfolio when volatility is computed from the cross-section of OTM puts is consistently insignificant.

When model-free volatility is computed from the full cross-section of OTM put and call option prices $(\mathrm{VF})$ the spread in average returns between the 1 st and the 5 th portfolios is marginally significant $(t$-statistic $=-1.85)$. The spread becomes more significant when the truncation level is higher than or equal to $1 \%$. Again, this is evidence that OTM put option prices, and especially deep OTM puts, do not contain useful information for capturing equity volatility risk. When innovations are measured with the VIX index the 5-1 spread in average returns is not statistically significant with a $t$-statistic of -1.25 and the alpha is only weakly significant with a $t$-statistic of -1.85 . In sharp contrast, the average spread in the case of VXO is highly significant with a $t$-statistic of -2.76 and an alpha with a $t$-statistic of -3.55 . This is again consistent with the previous results since VXO is computed from near the money implied volatilities and does not contain any information from OTM put option prices. Overall, the empirical results from the portfolio sorts provide strong evidence that OTM put option prices do not provide any useful information with respect to equity volatility risk.

Table IV reports the results from the portfolio sorts using model-free volatilities that capture left tail volatility risk. Again, innovations in model-free volatilities are proxied by the daily changes in volatility levels computed from equation (8). The portfolio formation procedure is the same with the one described previously. The spread in average returns between the 5 th quintile portfolio and the 1st quintile portfolio is highly insignificant in all cases.

\subsection{Fama-Macbeth Regressions}

To further test the validity of our empirical results, we calculate the prices of volatility risk using the Fama and Macbeth (1973) two-stage regression. The price of volatility risk is estimated for each one of the 21 corridor volatilities and the VIX and VXO indices. For each corridor volatility we construct 25 double sorted portfolios. First we sort according to the market beta and then we sort according to the volatility beta and we use the same procedure as the one outlined in section 4.1 for the single sorted portfolios. For each corridor volatility we use as test assets its corresponding 25 volatility sorted portfolios and as a volatility risk factor the spread in returns between portfolios with high and low beta volatility. ${ }^{3}$ The volatility factor portfolio is denoted as VOL and we use its monthly returns.

\footnotetext{
${ }^{3}$ The volatility factor is constructed from the 25 portfolios and it is equal to $1 / 5\left(\left(r_{P 5}+r_{P 10}+r_{P 15}+r_{P 20}+r_{P 25}\right)-\right.$ $\left.\left(\mathrm{r}_{\mathrm{P} 1}+\mathrm{r}_{\mathrm{P} 6}+\mathrm{r}_{\mathrm{P} 11}+\mathrm{r}_{\mathrm{P} 16}+\mathrm{r}_{\mathrm{p} 21}\right)\right)$, where $\mathrm{r}_{\mathrm{pi}}$ is the return of the $\mathrm{i} t$ portfolio.
} 
TABLE III

Volatility Sorted Portfolios

\begin{tabular}{|c|c|c|c|c|c|c|c|}
\hline Portfolio & $V F$ & $V P F$ & $V C F$ & Portfolio & $V 99$ & VP99 & VC99 \\
\hline 1 & 0.005 & 0.008 & 0.012 & 1 & 0.010 & 0.009 & 0.011 \\
\hline 2 & 0.005 & 0.009 & 0.009 & 2 & 0.009 & 0.008 & 0.010 \\
\hline 3 & 0.004 & 0.007 & 0.007 & 3 & 0.007 & 0.008 & 0.007 \\
\hline 4 & 0.004 & 0.008 & 0.007 & 4 & 0.007 & 0.007 & 0.007 \\
\hline 5 & 0.002 & 0.004 & 0.002 & 5 & 0.003 & 0.005 & 0.002 \\
\hline $5-1$ & -0.003 & -0.004 & -0.010 & $5-1$ & -0.007 & -0.004 & -0.009 \\
\hline t-stat & -1.855 & -1.373 & -2.649 & t-stat & -2.011 & -1.221 & -2.518 \\
\hline alpha & -0.009 & -0.007 & 0.000 & alpha & -0.009 & -0.007 & -0.011 \\
\hline t-stat & -2.549 & -2.019 & -3.330 & t-stat & -2.676 & -1.848 & -3.194 \\
\hline Portfolio & V95 & VP95 & VC95 & Portfolio & V90 & VP90 & VC90 \\
\hline 1 & 0.010 & 0.009 & 0.012 & 1 & 0.011 & 0.009 & 0.011 \\
\hline 2 & 0.009 & 0.008 & 0.009 & 2 & 0.009 & 0.009 & 0.010 \\
\hline 3 & 0.007 & 0.008 & 0.007 & 3 & 0.007 & 0.008 & 0.007 \\
\hline 4 & 0.007 & 0.007 & 0.007 & 4 & 0.007 & 0.007 & 0.007 \\
\hline 5 & 0.004 & 0.005 & 0.002 & 5 & 0.003 & 0.004 & 0.002 \\
\hline $5-1$ & -0.007 & -0.004 & -0.010 & $5-1$ & -0.008 & -0.005 & -0.009 \\
\hline t-stat & -1.912 & -1.172 & -2.557 & t-stat & -2.263 & -1.386 & -2.337 \\
\hline alpha & -0.009 & -0.007 & -0.011 & alpha & -0.011 & -0.007 & -0.011 \\
\hline t-stat & -2.629 & -1.822 & -3.226 & t-stat & -2.988 & -2.014 & -3.029 \\
\hline Portfolio & V85 & VP85 & VC85 & Portfolio & V80 & VP80 & VC80 \\
\hline 1 & 0.010 & 0.008 & 0.011 & 1 & 0.011 & 0.009 & 0.011 \\
\hline 2 & 0.010 & 0.009 & 0.010 & 2 & 0.009 & 0.009 & 0.010 \\
\hline 3 & 0.007 & 0.008 & 0.007 & 3 & 0.007 & 0.008 & 0.007 \\
\hline 4 & 0.007 & 0.006 & 0.007 & 4 & 0.007 & 0.006 & 0.007 \\
\hline 5 & 0.003 & 0.006 & 0.003 & 5 & 0.003 & 0.004 & 0.002 \\
\hline $5-1$ & -0.007 & -0.003 & -0.008 & $5-1$ & -0.008 & -0.005 & -0.009 \\
\hline t-stat & -1.967 & -0.772 & -1.988 & t-stat & -2.210 & -1.526 & -2.329 \\
\hline alpha & -0.009 & -0.004 & -0.011 & alpha & -0.011 & -0.007 & -0.011 \\
\hline t-stat & -2.691 & -1.405 & -2.654 & t-stat & -2.908 & -2.110 & -2.982 \\
\hline Portfolio & V75 & VP75 & VC75 & Portfolio & VIX & VXO & \\
\hline 1 & 0.012 & 0.009 & 0.011 & 1 & 0.010 & 0.012 & \\
\hline 2 & 0.010 & 0.010 & 0.010 & 2 & 0.009 & 0.010 & \\
\hline 3 & 0.007 & 0.008 & 0.007 & 3 & 0.008 & 0.009 & \\
\hline 4 & 0.006 & 0.006 & 0.007 & 4 & 0.008 & 0.007 & \\
\hline 5 & 0.003 & 0.003 & 0.003 & 5 & 0.005 & 0.003 & \\
\hline $5-1$ & -0.009 & -0.006 & -0.008 & $5-1$ & -0.005 & -0.010 & \\
\hline t-stat & -2.469 & -1.754 & -2.249 & t-stat & -1.252 & -2.762 & \\
\hline alpha & -0.011 & -0.009 & -0.011 & alpha & -0.007 & -0.011 & \\
\hline t-stat & -3.152 & -2.258 & -2.945 & t-stat & -1.855 & -3.554 & \\
\hline
\end{tabular}


TABLE III

(Continued)

This table reports the average monthly returns of quintile portfolios $1-5$. Every month we use daily data and regress individual stock excess returns on excess market returns and innovations on market volatility: $R_{i, t}-R_{f, t}=a_{i}+\beta_{i M} M K T_{t}+\beta_{i, V} \Delta V_{t}+\varepsilon_{i, t}$. Stocks are sorted into quintiles based on the regression coefficient $\beta_{i v}$, where quintile 1 has the lowest coefficient and quintile 5 has the highest coefficient. Within each quintile we form value-weighted portfolios based on stocks capitalization at the last day of the estimation period. We record the daily returns of each value-weighted portfolio over the next month and then the estimation window is rolled forward 1 month and the process is repeated. We repeat the estimation procedure for a total of 192 months. The row " $5-1$ " reports the difference in monthly returns between portfolio 5 and portfolio 1 . The row "alpha" reports Jensen's alpha with respect to the Fama-French three factor model augmented by the momentum factor of Carhart. The $t$-statistics are adjusted for autocorrelation and heteroskedasticy using the Newey and West (1987) estimator with 12 lags. The sample period is from January 1996 to December 2011. The model-free volatility which is computed from the segment of the cross-section of OTM put and call option prices that truncates the left and right tails of the underlying's risk-neutral return distribution by $1 \%$ is denoted as V99. The model-free volatility which is computed from the segment of the cross-section of OTM puts that truncates the left tail by $1 \%$ is denoted as VP99 and the model-free volatility which is computed from the segment of the cross-section of OTM calls that truncates the right tail by $1 \%$ is denoted as VC99. We similarly define model-free volatilities that correspond to $5 \%, 10 \%, 15 \%$, $20 \%$, and $25 \%$ truncation levels of the left and right tails of the undelrying's risk neutral distribution. VF, VPF, and VCF are calculated using the full cross-section of option prices ( $0 \%$ truncation).

In the first stage we estimate for each portfolio $i=1,2, \ldots, 25$ the factor loadings with respect to the market return and the spread between the high/low volatility beta portfolios using the full sample. We also control for the size factor (SMB), the value factor (HML). the momentum factor (UMD) and the liquidity factor (LIQ) of Pastor and Stambaugh (2003). The first stage regression is the following:

$$
\begin{aligned}
& R_{i, t}-R_{f, t}=a_{i}+\beta_{i M} M K T_{t}+\beta_{i H M L} H M L_{t}+\beta_{i S M B} S M B_{t} \\
& +\beta_{i U M D} U M D_{t}+\beta_{i L I Q} L I Q_{t}+\beta_{i V O L} V O L_{t}+\varepsilon_{i, t}
\end{aligned}
$$

TABLE IV

Volatility Tail Risk Sorted Portfolios

\begin{tabular}{lrrr}
\hline Portfolio & VPT1 & VPT5 & VPT10 \\
\hline 1 & 0.006 & 0.008 & 0.008 \\
2 & 0.008 & 0.008 & 0.008 \\
3 & 0.008 & 0.008 & 0.009 \\
4 & 0.008 & 0.008 & 0.007 \\
5 & 0.007 & 0.006 & 0.005 \\
$5-1$ & 0.001 & -0.002 & -0.003 \\
t-stat & 0.284 & -0.810 & -1.053 \\
\hline alpha & & & -0.004 \\
t-stat & 0.000 & -0.002 & -1.558 \\
\hline
\end{tabular}

This table reports the average monthly returns of quintile portfolios $1-5$. Every month we use daily data and regress individual stock excess returns on excess market returns and innovations on market volatility: $R_{i, t}-R_{f, t}=a_{i}+\beta_{i M} M K T+\beta_{i, v} \Delta V_{t}+\varepsilon_{i, t}$. Stocks are sorted into quintiles based on the regression coefficient $\beta_{i v}$, where quintile 1 has the lowest coefficient and quintile 5 has the highest coefficient. Within each quintile we form value-weighted portfolios based on stocks capitalization at the last day of the estimation period. We record the daily returns of each value-weighted portfolio over the next month and then the estimation window is rolled forward 1 month and the process is repeated. We repeat the estimation procedure for a total of 192 months. The row " $5-1$ " reports the difference in monthly returns between portfolio 5 and portfolio 1 . The row "alpha" reports Jensen's alpha with respect to the Fama-French three factor model augmented by the momentum factor of Carhart. The $t$-statistics are adjusted for autocorrelation and heteroskedasticy using the Newey and West (1987) estimator with 12 lags. The sample period is from January 1996 to December 2011. The model-free volatility which is computed from the segment of the the cross-section of OTM puts that corresponds to the $1 \%$ of the left tail of the underlying's risk-neutral return is denoted as VPT1, the model-free volatility which is computed from the segment of the cross-section of OTM puts that corresponds to the $5 \%$ of the left tail is denoted as VPT5 and the model-free volatility which is computed from the segment of the cross-section of OTM puts that corresponds to the $10 \%$ of the left tail is denoted as VPT10. 
In the second stage the market price of risk of each factor is estimated using monthly crosssectional regressions:

$$
\begin{aligned}
& \bar{R}_{i, j}-\bar{R}_{f, j}=\lambda_{0, j}+\beta_{i M} \lambda_{M, j}+\beta_{i H M L} \lambda_{H M L, j}+\beta_{i S M B} \lambda_{S M B, j} \\
& +\beta_{i, U M D} \lambda_{U M D, j}+\beta_{i, L I Q} \lambda_{L I Q, j}+\beta_{i, V O L} \lambda_{V O L, j}+e_{i, j}
\end{aligned}
$$

where, $\bar{R}_{i, j}$ is the monthly return of portfolio $i=1,2, \ldots, 25$ in month $j=1, \ldots, 192$. The estimates of the factor premiums $\lambda$ are obtained by averaging the monthly premiums, $\lambda=(1 / M) \sum_{j=1}^{M} \lambda_{j}$, where $M=192$. We compute the Fama-Macbeth $t$-statistics adjusted for autocorrelation and heteroskedasticy using the Newey and West (1987) estimator with 12 lags.

The results are reported in Table $\mathrm{V}$. The volatility risk premium is consistently significant only when the 25 volatility sorted portfolios and the volatility factor are constructed from volatilities that use the cross-section of OTM call options (only in the case of the VC75 portfolio the premium is insignificant). The cross sectional average volatility premium is around $-7 \%$ per annum which is somewhat smaller than the spread in average returns between the 5 th quintile portfolio and the 1 st quintile portfolio obtained from the portfolio sorting tests (around $-10 \%$ per annum). ${ }^{4}$ In contrast, the volatility risk premium computed from portfolios and spreads obtained from volatilities that use the cross-section of OTM put options is insignificant in all cases regardless of truncation levels.

\subsection{Factor Mimicking Aggregate Volatility Risk}

Similar to Ang, Hodrick, Xing, and Zhang (2006), we construct a mimicking factor that tracks changes in daily volatility innovations $\left(\Delta V_{t}\right)$. The factor is obtained from estimating the regression:

$$
\Delta V_{t}=a+b^{\prime} X_{t}+\varepsilon_{t}
$$

where, $X_{t}$ represent the return of base assets. The factor that mimics volatility innovations is given by $b^{\prime} X_{t}$. For each corridor volatility we use as base assets the excess returns of its corresponding 5 volatility sorted portfolios. The average monthly returns and the corresponding $t$-statistics of the factor-mimicking portfolios are reported in Table VI. Consistent with the previous results the monthly returns of the portfolios that track changes in volatilities computed from OTM call options are consistently negative and significant. The monthly returns of the portfolios that track changes in volatilities computed from OTM put options are insignificant or marginally significant up to the $20 \%$ truncation level. Table VII reports the results from single portfolios sorts. Portfolios sorts are based on the sensitivity to the volatility factor mimicking portfolios and the procedure is the same as the one described in section 4.1. The results are somewhat statistically weaker compared to the results in Table III. However, the spread in average returns between the 5th quintile portfolio and the 1 st quintile portfolio when volatility is computed from the cross-section of OTM calls is statistically significant at the $10 \%$ level and the alphas are also highly significant with $t$-statistics above 2 . The average spread when volatility is computed from the cross-section of OTM puts is in all cases insignificant. ${ }^{5}$

\footnotetext{
${ }^{4}$ This difference may be attributed to the lack of control variables (SMB, HML, UMD, and LIQ) in regression (9). ${ }^{5}$ We have also tested single portfolios sorts using factor mimicking portfolios for volatility risk in the left tail and the results were insignificant as in Table IV.
} 
TABLE V

Fama-Macbeth Regressions

\begin{tabular}{lccccrrr}
\hline & Con. & MKT & SMB & HML & UMD & LIQ & VOL \\
\hline VF & -0.002 & -0.004 & 0.011 & 0.007 & 0 & 0.002 & -0.004 \\
t-stat & -0.395 & -0.885 & 1.423 & 1.146 & -0.441 & 0.119 & -1.641 \\
VCF & 0.007 & -0.004 & 0.007 & -0.003 & 0.001 & -0.011 & -0.006 \\
t-stat & 1.45 & -0.923 & 0.941 & -0.451 & 2.125 & -0.779 & -2.575 \\
VPF & -0.001 & 0 & 0.004 & 0.008 & 0.001 & 0.024 & -0.002 \\
t-stat & -0.222 & -0.005 & 0.928 & 1.25 & 1.409 & 1.272 & -0.734 \\
& & & & & & &
\end{tabular}

\begin{tabular}{lcclllll} 
V99 & -0.002 & -0.003 & 0.01 & 0.01 & 0 & 0 & -0.004 \\
t-stat & -0.427 & -0.687 & 1.343 & 1.443 & 0.321 & 0.012 & -1.72 \\
VC99 & 0.007 & -0.004 & 0.009 & -0.001 & 0.001 & -0.011 & -0.005 \\
t-stat & 1.14 & -0.955 & 0.921 & -0.161 & 2.248 & -0.645 & -2.089 \\
VP99 & -0.003 & 0.001 & 0.001 & 0.007 & 0 & 0.033 & -0.001 \\
t-stat & -0.596 & 0.19 & 0.259 & 1.064 & 0.344 & 2.109 & -0.475 \\
\hline
\end{tabular}

\begin{tabular}{lcllllrr} 
V95 & -0.001 & -0.005 & 0.012 & 0.006 & 0 & 0.008 & -0.005 \\
t-stat & -0.206 & -0.977 & 1.582 & 0.768 & 0.243 & 0.535 & -1.866 \\
VC95 & 0.005 & -0.006 & 0.01 & -0.003 & 0.001 & -0.019 & -0.007 \\
t-stat & 1.019 & -1.31 & 1.14 & -0.379 & 0.918 & -1.406 & -3.305 \\
VP95 & 0 & -0.002 & 0.005 & 0.004 & 0 & 0.012 & -0.002 \\
t-stat & -0.001 & -0.521 & 0.757 & 0.561 & 0.024 & 0.908 & -0.851 \\
\hline
\end{tabular}

\begin{tabular}{llllllll} 
V90 & 0.001 & -0.005 & 0.01 & 0.006 & 0 & -0.003 & -0.005 \\
t-stat & 0.162 & -0.912 & 1.278 & 0.763 & 0.37 & -0.157 & -2.054 \\
VC90 & 0.005 & -0.005 & 0.008 & -0.003 & 0.001 & -0.009 & -0.007 \\
t-stat & 1.123 & -0.993 & 0.992 & -0.349 & 1.332 & -0.697 & -3.187 \\
VP90 & 0 & -0.002 & 0.005 & 0.005 & 0 & 0.013 & -0.002 \\
t-stat & -0.017 & -0.474 & 0.808 & 0.612 & 0.195 & 1.286 & -1.055 \\
\hline
\end{tabular}

\begin{tabular}{llllllrr} 
V85 & 0.003 & -0.004 & 0.002 & 0.001 & 0 & 0.015 & -0.004 \\
t-stat & 0.607 & -0.798 & 0.266 & 0.188 & 0.437 & 0.859 & -1.937 \\
VC85 & 0.005 & -0.005 & 0.009 & -0.001 & 0.001 & -0.011 & -0.005 \\
t-stat & 0.943 & -0.937 & 1.163 & -0.209 & 1.538 & -0.728 & -2.641 \\
VP85 & 0 & -0.002 & 0.003 & 0.005 & 0 & 0.007 & -0.002 \\
t-stat & 0.077 & -0.599 & 0.402 & 0.594 & -0.657 & 0.503 & -0.981 \\
\hline
\end{tabular}

\begin{tabular}{lllllrrr} 
V80 & 0.008 & -0.008 & 0.006 & -0.001 & 0 & -0.02 & -0.005 \\
t-stat & 1.831 & -1.581 & 0.737 & -0.187 & -0.069 & -2.156 & -2.419 \\
VC80 & 0.001 & -0.003 & 0.015 & -0.001 & 0.001 & 0.013 & -0.005 \\
t-stat & 0.14 & -0.554 & 1.798 & -0.09 & 1.972 & 0.764 & -2.552 \\
VP80 & -0.001 & -0.003 & 0.007 & 0.004 & -0.001 & -0.005 & -0.003 \\
t-stat & -0.182 & -0.584 & 1.17 & 0.594 & -0.612 & -0.546 & -1.01 \\
\hline & & & & & & & -0.012 \\
V75 & 0.005 & -0.008 & 0.008 & 0 & 0 & -0.736 & -2.826 \\
t-stat & 1.419 & -1.44 & 1.351 & -0.068 & -0.087 & -0.06 \\
\hline
\end{tabular}


TABLE V

(Continued)

\begin{tabular}{llllllll}
\hline & Con. & MKT & SMB & HML & UMD & LIQ & VOL \\
\hline VC75 & 0.007 & -0.004 & 0 & -0.002 & 0 & -0.016 & -0.003 \\
t-stat & 0.982 & -1.086 & -0.069 & -0.166 & 0.721 & -0.794 & -0.585 \\
VP75 & -0.001 & -0.003 & 0.008 & 0.005 & 0 & -0.003 & -0.004 \\
t-stat & -0.114 & -0.575 & 1.163 & 0.662 & 0.098 & -0.218 & -1.606 \\
& & & & & & & \\
VIX & 0.007 & -0.006 & 0.005 & 0 & 0.001 & -0.031 & -0.005 \\
t-stat & 1.314 & -1.171 & 0.642 & 0.06 & 1.485 & -1.925 & -1.811 \\
VXO & 0 & -0.005 & 0.009 & 0.003 & 0 & 0.013 & -0.005 \\
t-stat & 0.097 & -1.119 & 1.155 & 0.339 & 0.809 & 1.054 & -2.228 \\
\hline
\end{tabular}

The monthly risk premiums from Fama-MacBeth cross-sectional regressions using the monthly excess returns on the 25 volatility sorted portfolios. For each corridor volatility we use as test assets its corresponding 25 volatility sorted portfolios and as a volatility risk factor (VOL) the spread in returns between high/low volatility beta portfolios. We also control for the excess market return (MKT), the size factor (SMB), value factor (HML), the momentum factor (UMD) and the liquidity factor (LIQ). In the first stage, factor loadings are obtained from regressing portfolio returns on excess market returns, the control variables and the return of the VOL portfolio using the full sample over the time period January 1996 to December 2011. In the second stage, the monthly excess returns of the portfolios are regressed on the loadings every month to obtain the estimates of the market price of risk for each factor. We compute the Fama-Macbeth (FM) $t$-statistics adjusted for autocorrelation and heteroskedasticy using the Newey and West (1987) estimator with 12 lags.

These results provide further evidence that volatility from deep OTM put options is not priced in the cross section of equity returns.

\section{REALIZED VOLATILITY FORECASTING}

The results in the previous section suggest that model-free volatility computed from the cross-section of OTM call options may be a better proxy for future volatility. To test if this is indeed the case, we run predictive regressions to examine the forecasting ability of the alternative model-free volatility measures. We use one-month ahead realized standard deviation $(\sqrt{R V})$ as the dependent variable and the square-root of model-free volatilities computed from the cross- section of OTM put and call option prices, respectively, as independent variables. We also control for past realized volatility Again, we compute modelfree volatilities that correspond to $0 \%, 5 \%, 10 \%, 15 \%, 20 \%$, and $25 \%$ truncation levels of the left and right tails of the underlying's risk neutral distribution. We run the regressions using the following specification:

$$
\sqrt{R V_{t+1}}=\beta_{0}+\beta_{1} \sqrt{V P_{t}}+\beta_{2} \sqrt{V C_{t}}+\beta_{3} \sqrt{R V_{t}}+\varepsilon_{t+1}
$$

where, now $t$ denotes end-of-month observations. Realized volatility is computed using daily SPX returns within each month.

The coefficient estimates along with Newey and West (1987) $t$-statistics with 12 lags are reported in Table VIII. The coefficient $\beta_{1}$ is insignificant for all model-free volatilities computed from OTM put option prices. In contrast, the coefficient of the model-free volatility computed from OTM call option prices is highly significant regardless of truncation level. These results suggest that OTM call option prices subsume all relevant information for forecasting future SPX realized volatility. 
TABLE VI

Factor Mimicking Aggregate Volatility Risk

\begin{tabular}{|c|c|c|}
\hline & Mean & $t$-statistic \\
\hline FVF & -0.008 & -2.562 \\
\hline FVPF & -0.005 & -1.314 \\
\hline FVCF & -0.003 & -2.378 \\
\hline FV99 & -0.007 & -2.604 \\
\hline FVP99 & -0.005 & -1.330 \\
\hline FVC99 & -0.002 & -2.347 \\
\hline FV95 & -0.006 & -2.445 \\
\hline FVP95 & -0.004 & -1.481 \\
\hline FVC95 & -0.002 & -2.362 \\
\hline FV90 & -0.006 & -2.531 \\
\hline FVP90 & -0.003 & -1.680 \\
\hline FVC90 & -0.002 & -2.327 \\
\hline FV85 & -0.005 & -2.446 \\
\hline FVP85 & -0.003 & -1.840 \\
\hline FVC85 & -0.002 & -2.460 \\
\hline FV80 & -0.004 & -2.337 \\
\hline FVP80 & -0.002 & -1.913 \\
\hline FVC80 & -0.002 & -2.350 \\
\hline FV75 & -0.003 & -2.402 \\
\hline FVP75 & -0.002 & -2.129 \\
\hline FVC75 & -0.002 & -2.389 \\
\hline FVIX & -0.010 & -2.753 \\
\hline FVXO & -0.007 & -2.185 \\
\hline
\end{tabular}

Monthly returns from volatility factor mimicking portfolios. The portfolio that tracks changes in model-free volatility computed from the segment of the cross-section of OTM put and call option prices that truncates the left and right tails of the underlying's riskneutral return distribution by $1 \%$ is denoted as FV99. The portfolio that tracks changes in model-free volatility computed from the segment of the cross-section of OTM puts that truncates the left tail by $1 \%$ is denoted as FVP99 and the portfolio that tracks the model-free volatility which is computed from the segment of the cross-section of OTM calls that truncates the right tail by $1 \%$ is denoted as FVC99. We similarly define portfolios that track changes in model-free volatilities that correspond to 5\%, 10\%, $15 \%$, $20 \%$, and $25 \%$ truncation levels of the left and right tails of the underlying's risk neutral distribution. FVF, FVPF, and FVCF are portfolios that track changes in model-free volatilities computed from the full cross-section of option prices $(0 \%$ truncation).

\section{CONCLUSIONS}

In this paper we examine the price of volatility risk using SPX corridor implied volatility. We break total implied volatility into various components that capture market volatility over different intervals for the underlying asset price. This decomposition allows us to separate the incremental information of the various segments of the cross-section of OTM put and call option prices with respect to the pricing of systematic volatility risk. We find that only volatilities computed from the cross-section of OTM call option prices carry a significant 
TABLE VII

Volatility Factor Mimicking Sorted Portfolios

\begin{tabular}{|c|c|c|c|c|c|c|c|}
\hline Portfolio & $F V F$ & $F V P F$ & $F V C F$ & Portfolio & FV99 & FVP99 & FVC 99 \\
\hline 1 & 0.009 & 0.008 & 0.011 & 1 & 0.009 & 0.007 & 0.011 \\
\hline 2 & 0.009 & 0.007 & 0.011 & 2 & 0.008 & 0.009 & 0.010 \\
\hline 3 & 0.008 & 0.007 & 0.007 & 3 & 0.007 & 0.008 & 0.008 \\
\hline 4 & 0.006 & 0.008 & 0.006 & 4 & 0.007 & 0.007 & 0.006 \\
\hline 5 & 0.006 & 0.006 & 0.003 & 5 & 0.006 & 0.006 & 0.003 \\
\hline $5-1$ & -0.003 & -0.002 & -0.009 & $5-1$ & -0.003 & -0.001 & -0.008 \\
\hline t-stat & -0.614 & -1.373 & -1.871 & t-stat & -0.670 & -0.252 & -1.819 \\
\hline alpha & -0.005 & -0.005 & -0.011 & alpha & -0.005 & -0.004 & -0.011 \\
\hline t-stat & -1.152 & -1.079 & -2.583 & t-stat & -1.202 & -0.856 & -2.566 \\
\hline Portfolio & FV95 & FVP95 & FVC95 & Portfolio & FV90 & FVP90 & FVC90 \\
\hline 1 & 0.009 & 0.005 & 0.010 & 1 & 0.009 & 0.006 & 0.012 \\
\hline 2 & 0.009 & 0.009 & 0.010 & 2 & 0.009 & 0.009 & 0.011 \\
\hline 3 & 0.007 & 0.007 & 0.007 & 3 & 0.006 & 0.007 & 0.008 \\
\hline 4 & 0.006 & 0.007 & 0.007 & 4 & 0.007 & 0.007 & 0.005 \\
\hline 5 & 0.007 & 0.008 & 0.004 & 5 & 0.006 & 0.008 & 0.003 \\
\hline $5-1$ & -0.003 & 0.003 & -0.006 & $5-1$ & -0.003 & 0.002 & -0.009 \\
\hline t-stat & -1.277 & 0.765 & -1.348 & t-stat & -0.681 & 0.403 & -1.926 \\
\hline alpha & -0.006 & 0.084 & -0.009 & alpha & -0.006 & -0.001 & -0.012 \\
\hline t-stat & -2.629 & 0.000 & -2.019 & t-stat & -1.343 & -0.316 & -2.668 \\
\hline Portfolio & FV85 & FVP85 & FVC85 & Portfolio & FV80 & FVP80 & FVC80 \\
\hline 1 & 0.009 & 0.008 & 0.011 & 1 & 0.009 & 0.006 & 0.011 \\
\hline 2 & 0.008 & 0.008 & 0.009 & 2 & 0.009 & 0.008 & 0.010 \\
\hline 3 & 0.008 & 0.006 & 0.009 & 3 & 0.008 & 0.007 & 0.008 \\
\hline 4 & 0.006 & 0.006 & 0.006 & 4 & 0.004 & 0.008 & 0.006 \\
\hline 5 & 0.007 & 0.009 & 0.003 & 5 & 0.006 & 0.006 & 0.003 \\
\hline $5-1$ & -0.002 & 0.001 & -0.009 & $5-1$ & -0.003 & -0.001 & -0.008 \\
\hline t-stat & -0.529 & 0.132 & -1.845 & t-stat & -0.636 & -0.116 & -2.329 \\
\hline alpha & -0.005 & -0.002 & -0.011 & alpha & -0.006 & -0.003 & -0.011 \\
\hline t-stat & -1.226 & -0.558 & -2.508 & t-stat & -1.302 & -0.639 & -2.425 \\
\hline Portfolio & FV75 & FVP75 & FVC75 & Portfolio & FVIX & FVXO & \\
\hline 1 & 0.008 & 0.009 & 0.012 & 1 & 0.009 & 0.010 & \\
\hline 2 & 0.007 & 0.009 & 0.010 & 2 & 0.008 & 0.009 & \\
\hline 3 & 0.008 & 0.008 & 0.008 & 3 & 0.008 & 0.008 & \\
\hline 4 & 0.008 & 0.006 & 0.005 & 4 & 0.008 & 0.008 & \\
\hline 5 & 0.007 & 0.006 & 0.001 & 5 & 0.004 & 0.004 & \\
\hline $5-1$ & -0.001 & -0.003 & -0.011 & $5-1$ & -0.005 & -0.006 & \\
\hline t-stat & -0.364 & -0.793 & -2.490 & t-stat & -1.230 & -1.359 & \\
\hline alpha & -0.001 & -0.005 & -0.014 & alpha & -0.008 & -0.007 & \\
\hline t-stat & -0.295 & -1.280 & -3.209 & t-stat & -1.742 & -1.810 & \\
\hline
\end{tabular}


This table reports the average monthly returns of quintile portfolios 1-5. Every month we use daily data and regress individual stock excess returns on excess market returns and the returns of the factor that mimics aggregate volatility risk: $R_{i, t}-R_{f, t}=a_{i}+\beta_{i M} M K T_{t}+\beta_{i, v} F V_{t}+\varepsilon_{i, t}$. Stocks are sorted into quintiles based on the regression coefficient $\beta_{i v}$, where quintile 1 has the lowest coefficient and quintile 5 has the highest coefficient. Within each quintile we form value-weighted portfolios based on stocks capitalization at the last day of the estimation period. We record the daily returns of each value-weighted portfolio over the next month and then the estimation window is rolled forward 1 month and the process is repeated. We repeat the estimation procedure for a total of 192 months. The row " $5-1$ " reports the difference in monthly returns between portfolio 5 and portfolio 1 . The row "alpha" reports Jensen's alpha with respect to the Fama-French three factor model augmented by the momentum factor of Carhart. The $t$-statistics are adjusted for autocorrelation and heteroskedasticy using the Newey and West (1987) estimator with 12 lags. The sample period is from January 1996 to December 2011. The portfolio that tracks changes in model-free volatility computed from the segment of the cross-section of OTM puts that truncates the left tail by $1 \%$ is denoted as FVP99 and the portfolio that tracks the model-free volatility which is computed from the segment of the cross-section of OTM calls that truncates the right tail by $1 \%$ is denoted as FVC99. We similarly define portfolios that track changes in model-free volatilities that correspond to $5 \%, 10 \%$, $15 \%, 20 \%$, and $25 \%$ truncation levels of the left and right tails of the underlying's risk neutral distribution. FVF, FVPF, and FVCF are portfolios that track changes in model-free volatilities computed from the full cross-section of option prices ( $0 \%$ truncation).

negative risk premium in the cross-section of stock returns. We also find that they contain all relevant information for forecasting future realized volatility.

Our empirical results provide strong evidence that SPX out-of-the money put option prices do not contain useful information for capturing systematic volatility risk in equity returns. These results provide evidence that equity market and the out-of-the-money index

TABLE VIII

Predicting Future Realized Volatility

\begin{tabular}{|c|c|c|c|c|c|c|c|}
\hline & 100 & 99 & 95 & 90 & 85 & 80 & 75 \\
\hline Constant & $\begin{array}{l}-0.02 \\
(-2.73)\end{array}$ & $\begin{array}{l}-0.02 \\
(-2.35)\end{array}$ & $\begin{array}{l}-0.02 \\
(-2.10)\end{array}$ & $\begin{array}{l}-0.02 \\
(-1.92)\end{array}$ & $\begin{array}{c}-0.02 \\
(-1.64)\end{array}$ & $\begin{array}{l}-0.02 \\
(-1.33)\end{array}$ & $\begin{array}{c}-0.01 \\
(-1.25)\end{array}$ \\
\hline VP & $\begin{array}{l}-0.16 \\
(-0.45)\end{array}$ & $\begin{array}{l}-0.17 \\
(-0.45)\end{array}$ & $\begin{array}{l}-0.19 \\
(-0.47)\end{array}$ & $\begin{array}{l}-0.16 \\
(-0.39)\end{array}$ & $\begin{array}{c}-0.08 \\
(-0.20)\end{array}$ & $\begin{array}{l}-0.04 \\
(-0.09)\end{array}$ & $\begin{array}{c}0.07 \\
(0.2)\end{array}$ \\
\hline VC & $\begin{array}{c}1.11 \\
(3.19)\end{array}$ & $\begin{array}{c}1.13 \\
(3.02)\end{array}$ & $\begin{array}{c}1.19 \\
(3.04)\end{array}$ & $\begin{array}{c}1.2 \\
(3.02)\end{array}$ & $\begin{array}{c}1.13 \\
(3.13)\end{array}$ & $\begin{array}{c}1.14 \\
(2.87)\end{array}$ & $\begin{array}{c}1.07 \\
(3.77)\end{array}$ \\
\hline RV & $\begin{array}{c}0.38 \\
(2.45)\end{array}$ & $\begin{array}{c}0.38 \\
(2.51)\end{array}$ & $\begin{array}{c}0.37 \\
(2.51)\end{array}$ & $\begin{array}{c}0.36 \\
(2.55)\end{array}$ & $\begin{array}{c}0.36 \\
(2.58)\end{array}$ & $\begin{array}{c}0.36 \\
(2.62)\end{array}$ & $\begin{array}{c}0.36 \\
(2.62)\end{array}$ \\
\hline Adj. $R^{2}$ & 0.58 & 0.58 & 0.58 & 0.58 & 0.58 & 0.58 & 0.58 \\
\hline Constant & $\begin{array}{l}-0.04 \\
(-2.01)\end{array}$ & $\begin{array}{l}-0.04 \\
(-1.91)\end{array}$ & $\begin{array}{l}-0.04 \\
(-1.81)\end{array}$ & $\begin{array}{l}-0.04 \\
(-1.71)\end{array}$ & $\begin{array}{c}-0.04 \\
(-1.59)\end{array}$ & $\begin{array}{l}-0.04 \\
(-1.42)\end{array}$ & $\begin{array}{l}-0.03 \\
(-1.36)\end{array}$ \\
\hline VP & $\begin{array}{c}0.04 \\
(0.17)\end{array}$ & $\begin{array}{c}0.03 \\
(0.12)\end{array}$ & $\begin{array}{c}0.04 \\
(0.12)\end{array}$ & $\begin{array}{c}0.06 \\
(0.18)\end{array}$ & $\begin{array}{c}0.15 \\
(0.42)\end{array}$ & $\begin{array}{c}0.21 \\
(0.51)\end{array}$ & $\begin{array}{c}0.35 \\
(0.98)\end{array}$ \\
\hline VC & $\begin{array}{c}1.51 \\
(3.02)\end{array}$ & $\begin{array}{c}1.54 \\
(2.88)\end{array}$ & $\begin{array}{c}1.59 \\
(2.85)\end{array}$ & $\begin{array}{c}1.62 \\
(2.68)\end{array}$ & $\begin{array}{c}1.59 \\
(2.62)\end{array}$ & $\begin{array}{c}1.62 \\
(2.42)\end{array}$ & $\begin{array}{l}1.58 \\
(2.7)\end{array}$ \\
\hline Adj. $R^{2}$ & 0.55 & 0.55 & 0.55 & 0.55 & 0.55 & 0.55 & 0.55 \\
\hline
\end{tabular}

Coefficient estimates from the regression: $\sqrt{R V_{t+1}}=\beta_{0}+\beta_{1} \sqrt{V P_{t}}+\beta_{2} \sqrt{V C_{t}}+\beta_{3} \sqrt{R V_{t}}+\varepsilon_{t+1}$, where, $V P_{t}$ and $V C_{t}$ are modelfree volatilities computed from the cross-section of OTM put and call option prices, respectively. Columns denote the truncation of the underlying's risk-neutral return distribution. Model-free volatilities that are computed using the full cross-section of option prices are in the first column (100). The model-free volatilities which are computed from the segment of the cross-section of OTM put and call option prices that truncates the left and right tails of the underlying's risk-neutral return distribution by $1 \%$ are in the second column (99). We similarly define model-free volatilities that correspond to $5 \%, 10 \%, 15 \%, 20 \%$, and $25 \%$ truncation levels of the left and right tails of the undelrying's risk neutral distribution. The $t$-statistics reported in parentheses are corrected for autocorrelation and heteroskedasticity using the Newey and West (1987) estimator with 12 lags. The data are end-of-month observations and the sample period is from January 1996 to December 2011. 
put option market are segmented due to market imperfections. One possible explanation of our results is provided by Bollen and Whaley (2004) and Garleanu, Pedersen and Poteshman (2009) which show that out-of-the money index put option prices are driven mainly by the demand pressure by hedgers who seek portfolio insurance.

\section{REFERENCES}

Adrian, T., \& Rosenberg, J. (2008). Stock returns and volatility: Pricing the short-run and long-run components of market risk. Journal of Finance, 63, 2997-3030.

Andersen, T. G., \& Bondarenko, O. (2010). Dissecting the pricing of equity index volatility. Working Paper, Northwestern University and University of Illinois at Chicago.

Andersen, T. G., Bondarenko O., \& Gonzalez-Perez, M. T. (2015). Exploring return dynamics via corridor implied volatility, Review of Financial Studies, forthcoming.

Ang, A., Hodrick, R. J., Xing, Y., \& Zhang, X. (2006). The cross-section of volatility and expected returns. Journal of Finance, 61, 259-299.

Bakshi, G., \& Kapadia, N. (2003). Delta-Hedged gains and the negative market volatility risk premium. Review of Financial Studies, 16, 527-566.

Bates, D. (2000). Post-' 87 crash fears in the S\&P 500 futures option market. Journal of Econometrics, 94, $181-238$.

Bates, D. (2008). The market for crash risk. Journal of Economic Dynamics and Control, 32, 2291-2321.

Black, F., \& Scholes, M. (1973). The pricing of options and corporate liabilities. Journal of Political Economy, 81, 637-659.

Bollen, N. P., \& Whaley, R. E. (2004). Does net buying pressure affect the shape of implied volatility functions. Journal of Finance, 59, 711-753.

Britten-Jones, M., \& Neuberger, A. (2000). Option prices, implied price processes, and stochastic volatility. Journal of Finance, 55, 839-866.

Carhart, M. M. (1997). On persistence in mutual fund performance. Journal of Finance, 52, 57-82.

Carr, P., \& Madan, D. (1998). Towards a theory of volatility trading. In R. Jarrow (Ed.), Volatility: New estimation techniques for pricing derivatives (pp. 458-476). London: RISK Publications.

Carr, P., \& Wu, L. (2009). Variance risk premiums. Review of Financial Studies, 22, 1311-1341.

Chernov, M., \& Ghysels, E. (2000). A study towards a unified approach to the joint estimation of objective and risk neutral measures for the purpose of options valuation. Journal of Financial Economics, 56, 407-458.

Cremers, M., Halling, M., \& Weinbaum, D. (2013). Aggregate jump and volatility risk in the cross-section of stock returns. Journal of Finance, forthcoming.

DeLisle, R. J., Doran, J. S., \& Peterson, D. R. (2011). Asymmetric pricing of implied systematic volatility in the crosssection of expected returns. Journal of Futures Markets, 31, 34-54.

Eraker, B. (2004). Do Equity Prices and Volatility Jump? Reconciling Evidence from Spot and Option Prices. Journal of Finance, 59, 1367-1403.

Fama, E., \& French, K. (1993). Common risk factors in the returns on stocks and bonds. Journal of Financial Economics, 33, 3-56.

Fama, E., \& MacBeth, J. D. (1973). Risk, return, and equilibrium: Empirical tests. Journal of Political Economy, 81, $607-636$.

Garleanu, N., Pederson, L. H., \& Poteshman, A. (2009). Demand-based option pricing. Review of Financial Studies, 22, 4259-4299.

Jackwerth, J. C. (2000). Recovering risk aversion from option prices and realized returns. Review of Financial Studies, 13, 433-451.

Jiang, G. J., \& Tian, Y. S. (2007). Extracting model-free volatility from option prices: An examination of the vix index. Journal of Derivatives, 14, 1-26.

Jones, C. S. (2006). A nonlinear factor analysis of S\&P 500 index options returns. Journal of Finance, 61, 2325-2363.

Newey, W. K., \& West, K. D. (1987). A simple, positive semi-definite, heteroskedasticity and autocorrelation consistent covariance matrix. Econometrica, 55, 703-708.

Pan, J. (2002). The jump-risk premia implicit in options: Evidence from an integrated time-series study. Journal of Financial Economics, 63, 3-50.

Pastor, L., \& Stambaugh, R. F. (2003). Liquidity risk and expected stock returns. Journal of Political Economy, 111 , $642-685$.

Rubinstein, M. (1994). Implied binomial trees. Journal of Finance, 49, 771-818.

Xing, Y., Zhang, X., \& Zhao, R. (2010). What does individual option volatility smirk tell us about future equity returns. Journal of Financial and Quantitative Analysis, 45, 641-662. 